\title{
Suggested and Preferred Amount of Clothing in a Winter Indoor Condition
}

\author{
Huen Sup Shim • Woon Seon Jeong** \\ Korea Institute of Industrial Technology \\ *Dept. of Clothing \& Textiles, Andong National University \\ Received September 29, 2011; Revised November 9, 2011; Accepted December 1, 2011
}

\begin{abstract}
This study proposes the suggested amount of clothing (SAC) and examines the preferred amount of clothing (PAC) for thermal comfort in mild cold conditions. Six male and nine female college students were systematically exposed to mild cold conditions by reducing the amount of clothing (Step I, 1.2clo $\rightarrow$ Step II, 1.0 clo $\rightarrow$ Step III, 0.8clo $\rightarrow$ Step IV, 0.7clo). The subjects were then asked to adjust the amount of clothing to attain overall thermal comfort until they maintained thermal comfort for 10 minutes without changing the amount of clothing (Step V). The experiment was carried out in a climatic chamber at $19.5^{\circ} \mathrm{C}, 50 \%$ R.H. Body composition was measured and individual cold climate adaptability was surveyed before starting the experiment. Rectal temperature $\left(\mathrm{T}_{\mathrm{re}}\right)$, skin temperature $\left(\mathrm{T}_{\mathrm{sk}}\right)$, and oxygen consumption $\left(\dot{\mathrm{V}} \mathrm{O}_{2}\right)$ were measured and the overall thermal sensation was voted in each step. PAC was obtained from the garments weight selected by each subject in Step V. SAC was proposed based on the change of oxygen consumption $\left.(\Delta \dot{\mathrm{VO}})_{2}\right)$. As a result, males showed higher $\overline{\mathrm{T}}_{\mathrm{sk}}$ and greater $\dot{\mathrm{V}} \mathrm{O}_{2}$ than females $(p<.01)$. SAC obtained from $\dot{\mathrm{V}} \mathrm{O}_{2}$ were 652.0 (SE $3.9) \mathrm{g} / \mathrm{m}^{2}$ for males and 766.0 (SE 2.5) $\mathrm{g} / \mathrm{m}^{2}$ for females and it was significantly different between groups $(p<.01)$. PAC of males and females were 1.6 and 1.5 times heavier than SAC. In conclusion, females were more sensitive to the cold stress and recommended larger amount of clothing than males.
\end{abstract}

Key words: Body composition, Skeletal muscle mass, Percent body fat, Suggested amount of clothing, Preferred amount of clothing

\section{Introduction}

The ambient temperature that human body increases oxygen consumption to keep the body temperature constant is $27-28^{\circ} \mathrm{C}$, which is called critical temperature (Scholander et al., 1950). When the ambient temperature becomes lower than that, human body reduces the heat dissipation from skin surface by vasoconstriction and increases the metabolic heat production. When the ambient temperature is higher than the critical temperature, human can maintain thermoregulatory homeostasis by increasing heat dissipation from

\footnotetext{
${ }^{\dagger}$ Corresponding author

E-mail: wsj@andong.ac.kr

This work was supported by the Korea Research Foundation (KRF) grant funded by the Korea government (MEST) (No. 2009-0068187).
}

skin surface through vasodilation and sweat production. The thermoneutral ambient temperature can be expanded by adjusting clothing layers, and controlling the intensity of heating and air conditioning and muscular work.

Researchers have had an interest in the effect of body composition on the thermoregulatory responses of human body (Glickman-Weiss et al., 1998; Glickman-Weiss et al., 1999; LeBlanc, 1975; Prisby et al., 2000; Prisby et al., 1999). It is well known that body fat is a significant factor in the sensitivity to a cold stress (LeBlanc, 1975). It has been found that people with greater body fat were able to attain their core temperature constant while they kept their skin temperature lower than the normal body fat group when they were exposed to a cold stress (Glickman-Weiss et al., 1998; Glickman-Weiss et al., 1999; Prisby et al., 
2000; Prisby et al., 1999).

However, the effect of body composition on the cold stress may work differently in men and women. McArdle et al. (1984) found that men with greater body fat were able to maintain the homeostasis without shivering in the cold water, but the lower body fat group wasn't able to maintain the core temperature. Stock et al. (2004) stated in their review article that women experienced greater reduction in core temperature when men and women with similar adiposity were exposed to a cold stress. Glickman-Weiss et al. (1991) found that low fat men maintained similar rectal temperature compared to high fat men and they explained it was resulted from a significantly greater shivering thermogenesis. When a similar study was done with female subjects, high fat group showed higher rectal temperature and insulation value than low fat group with no difference in metabolic rate (Glickman-Weiss et al., 1999). They concluded that the impact of body composition on energy expenditure to maintain rectal temperature during cold exposure appears to differ between low fat and high fat males and females. These experiments were mostly done in an acute air temperature or cold water immersion, at which shivering thermogenesis occurred. These findings explain the skeletal muscle mass in a human body composition is also a significant factor for the thermoregulation in a cold stress. Toner et al. (1986) studied the tissue insulation on the subjects with similar percent body fat but different surface area to mass ratios and total body mass. They found that the tissue insulation was higher in the larger individuals and explained it with a greater volume of muscle tissue and a larger muscle mass in the limbs. Women have larger body surface area to mass ratio, tend to have relatively small muscle mass, and have greater body fat especially in the limbs than males (Stock et al., 2004). Thus the comparison of thermoregulatory response of males and females would be more complex.

Not many researchers have had an interest in the studies in a mild cold condition where people are exposed mostly in a daily life. Dauncey (1981) and Celi et al. (2010) compared the average energy metabolism in a mild cold and warm air temperature exposure for 12-24 hours and found that mild cold tem- perature exposure resulted in significantly higher energy metabolism than warm temperature exposure.

The thermoneutral ambient temperature seemed to get narrow because a body is mostly exposed to the comfortable ambient condition with the help of clothing and air conditioning in buildings. In this study, we focused on the adjustment of garment wearing as a tool for enhancing climate adaptability because it mainly affects individual's climate adaptability. As Scholander et al. (1950) showed the importance of the energy metabolism to maintain body temperature in the cold, the oxygen consumption would be a good index for determining the suggested amount of clothing. The purpose of this study was to propose the suggested amount of clothing and to observe the preferred amount of clothing for thermal comfort in the mild cold.

\section{Experimental}

\section{Subjects}

Six young male and nine female university students volunteered as subjects for this study. Prior to participation, subjects were informed and signed a consent form. Females participated in the experiment in the follicular phase. The physical characteristics of the subjects are presented in $<$ Table $1>$. The bioelectrical impedance analysis (InBody 4.0, Biospace Co., Korea) was used to measure the height and weight, and to obtain skeletal muscle mass, and percent body fat. There were significant differences in the body composition between the groups. Males in bigger body size had more skeletal muscle mass and lower percent body fat than females $(p<.01)$.

\section{Measurements}

Rectal temperature $\left(\mathrm{T}_{\mathrm{re}}\right)$ and skin temperature $\left(\mathrm{T}_{\mathrm{sk}}\right)$ at seven body regions (forehead, chest, forearm, hand, thigh, leg, foot) were measured every minute using the thermistor (LT-8A, Gram Co., Japan), and sedentary oxygen consumption $\left(\mathrm{V}_{2}\right)$ was obtained using the pulmonary function equipment (Quark $b^{2}$, COSMED Co., Italy) during the whole test period. The gas analyzer was calibrated prior to testing with standard ref- 
Table 1. Physical characteristics of the subjects

\begin{tabular}{c|l|l|l|l|l|l|l}
\hline \hline Subject & \multicolumn{1}{|c|}{ Age $(\mathrm{yr})$} & Height $(\mathrm{cm})$ & Weight $(\mathrm{kg})$ & Body fat $(\%)$ & $\mathrm{SMM}^{\mathrm{a}}(\mathrm{kg})$ & $\mathrm{BSA}^{\mathrm{b}}\left(\mathrm{m}^{2}\right)$ & $\mathrm{BSAMR}^{\mathrm{c}}\left(\mathrm{m}^{2} / \mathrm{kg}^{2}\right.$ \\
\hline Male $(\mathrm{n}=6)$ & $22.5(0.3)$ & $176.7(1.8)$ & $72.5(3.1)$ & $21.2(2.7)$ & $32.3(1.1)$ & $1.6(0.0)$ & $0.022(0.001)$ \\
\hline Female $(\mathrm{n}=9)$ & $19.2(0.3)^{* *}$ & $164.6(1.1)^{* *}$ & $54.5(1.1)^{* *}$ & $27.4(0.9)^{*}$ & $20.6(0.4)^{* *}$ & $1.3(0.0)^{* *}$ & $0.025(0.000)^{* *}$ \\
\hline
\end{tabular}

Values are mean (SE). ${ }^{*} p<.05, * * p<.01$ compared to male subject.

${ }^{\mathrm{a}}$ Skeletal muscle mass, ${ }^{\mathrm{b}}$ Body surface area $=$ Height $(\mathrm{cm}){ }^{0.725} \times$ Weight $(\mathrm{kg}){ }^{0.425} \times 0.007246$, ${ }^{\mathrm{c}}$ Body surface area to mass ratio $=\mathrm{BSA} / \mathrm{Weight}$

erence gas. The mean values of $\mathrm{T}_{\mathrm{re}}, \mathrm{T}_{\mathrm{sk}}$, and $\dot{\mathrm{V}} \mathrm{O}_{2}$ were calculated from the experimental data obtained during 5 minutes before the end of each period.

\section{Calculations}

The mean skin temperature $\left(\bar{T}_{\mathrm{sk}}\right)$ was calculated from the $\mathrm{T}_{\mathrm{sk}}$ using the Hardy and DuBois equation:

$$
\begin{aligned}
\overline{\mathrm{T}}_{\text {sk }}= & 0.07 \mathrm{~T}_{\text {head }}+0.35 \mathrm{~T}_{\text {chest }}+0.14 \mathrm{~T}_{\text {forearm }}{ }^{+} \\
& 0.05 \mathrm{~T}_{\text {hand }}+0.19 \mathrm{~T}_{\text {thigh }}+0.13 \mathrm{~T}_{\text {leg }}+0.07 \mathrm{~T}_{\text {foot }}
\end{aligned}
$$

The thermal insulation of the ensemble was estimated from the following equation (McCullough et al., 1985). $\mathrm{I}_{\text {cle }}=0.432 \times \mathrm{AWT}+0.250$, where $\mathrm{I}_{\text {cle }}$ is the ensemble insulation (clo) and AWT is the ensemble weight $(\mathrm{kg})$ without shoes.

\section{Subjective Votes}

The cold climate adaptability of the subjects was questioned on 3-item questionnaire using a 4-point likert scale (1. absolutely not true, 2 . not true, 3 . true, 4 . absolutely true). The subjective thermal sensation (1: very hot,
2: hot, 3: warm, 4: slightly warm, 5: neutral, 6: slightly cool, 7: cool, 8: cold, 9: very cold) was voted every 5 min during the whole test period.

\section{Experimental Procedures}

After the subjects arrived at the test room, they took off their own garments and changed to a light gown to measure their body size and body composition. Then they ate a light standard meal. Then they took a rest for one hour after they changed to the experimental basic ensemble which is shown in $<$ Table $2>$.

During the rest, subjects were asked to reply to the questionnaire consisting of individual's cold climate adaptability. After the rest, they entered the climatic chamber controlled at 19.5, 50\%R.H. They inserted the probe for rectal temperature to a depth of about $10 \mathrm{~cm}$ from the anal sphincter. The skin temperature sensors were attached to 7 body regions. And they wore the mask for measuring the oxygen consumption. The experiment consisted of 5 steps and each step lasted for $15 \mathrm{~min}$. The subjects experienced gradual reduction of clothing amount at each step. The test protocol is diagrammed

\begin{tabular}{|c|c|c|c|c|c|c|}
\hline & Ensemble type & Garment & Type & Material & Weight $^{\mathrm{a}}(\mathrm{g})$ & Insulation (clo) \\
\hline \multirow{5}{*}{ Baseline } & \multirow{5}{*}{ Basic ensemble } & Undershirt & Sleeveless & Cotton $100 \%$ & & \\
\hline & & T-shirt (thin) & Long sleeved & Cotton $100 \%$ & & \\
\hline & & Trousers & Long & Cotton $100 \%$ & & \\
\hline & & Shirt & Long sleeved & Cotton $100 \%$ & & \\
\hline & & Socks & Ankle length & Cotton, Acrylic, Nylon & & \\
\hline \multicolumn{5}{|c|}{ (Total) } & 930 & 0.7 \\
\hline Step I & $\begin{array}{l}\text { Basic ensemble+Cardigan } \\
\text { T-shirt (thick) } \\
\text { Jacket }\end{array}$ & $\begin{array}{l}\text { Cardigan } \\
\text { T-shirt (thick) } \\
\text { Jacket }\end{array}$ & $\begin{array}{l}\text { Long sleeved } \\
\text { Long sleeved } \\
\text { Long sleeved }\end{array}$ & $\begin{array}{l}\text { Acrylic } 100 \% \\
\text { Cotton } 100 \% \\
\text { Polyester } 100 \%\end{array}$ & 2,149 & 1.2 \\
\hline Step II & Step I-Jacket & & & & 1,800 & 1.0 \\
\hline Step III & Step II-T-shirt (thick) & & & & 1,261 & 0.8 \\
\hline Step IV & Basic ensemble & & & & 930 & 0.7 \\
\hline
\end{tabular}

Table 2. Experimental garments description

${ }^{\mathrm{a}}$ Mean ensemble weight of male and female 


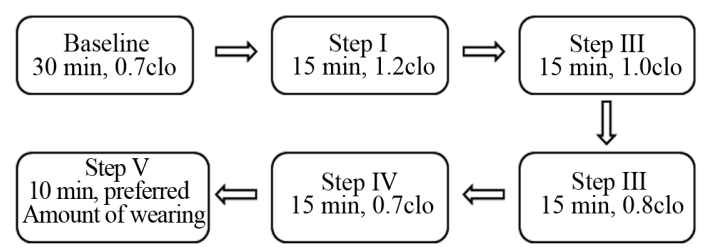

Fig. 1. Experimental test protocol.

in $<$ Fig. $1>$.

Once the experiment started, the subjects rested for $30 \mathrm{~min}$ with the basic ensemble (Baseline; 0.7clo) for equilibrium. After Baseline, cardigan, T-shirt (thick), and jacket were added to the basic ensemble (Step I, 1.2clo). After that, the amount of clothing was reduced step by step (Step II, 1.0clo $\rightarrow$ Step III, 0.8clo $\rightarrow$ Step IV, $0.7 \mathrm{clo}$ ). After finishing all the test steps, the subjects were asked to freely adjust the amount of clothing to attain overall thermal sensation until they kept thermal comfort for 10 minutes without changing the amount of clothing (Step V). For this, several kinds of garment items such as jacket, cardigan, shirt, mufflers, socks, gloves were displayed to allow the subjects choose to wear easily. As soon as the whole experiment was over, the garment items selected in Step V were weighed to determine the preferred amount of clothing (PAC). Thus PAC was calculated from the total weight of garments worn in Step V divided by body surface area. In this study, on the other hand, we defined suggested amount of clothing (SAC) in the cold as the minimum of clothing with that the body temperature was regulated by only cutaneous vascular responses. Basically, SAC is based on the change of oxygen consumption as Scholander et al. (1950) deter- mined critical temperature based on the point of increase in oxygen consumption. In a similar way to PAC, SAC was calculated from the total weight of garments divided by body surface area.

\section{Data Analysis}

The sum and the percentage of the positive answers on the cold climate adaptability were calculated. The data were analyzed by t-test and ANOVA using windows PASW 19.0K to determine whether males and females showed significant differences in the thermophysiological responses.

\section{Results}

\section{Physiological Responses}

$<$ Table $3>$ shows the oxygen consumption $\left(\dot{\mathrm{V}} \mathrm{O}_{2}\right)$, rectal temperature $\left(\mathrm{T}_{\mathrm{re}}\right)$, and mean skin temperature $\left(\overline{\mathrm{T}}_{\mathrm{sk}}\right)$ during Step I through Step IV. Males showed significantly higher $\overline{\mathrm{T}}_{\mathrm{sk}}$ and $\mathrm{T}_{\mathrm{re}}$ during the whole test periods. Males showed higher $\dot{\mathrm{V}} \mathrm{O}_{2}$ than females with no significant difference. The mean respiratory quotient obtained during the whole tests was 0.87 . As seen in $\langle$ Fig. 2$\rangle, \dot{\mathrm{V}} \mathrm{O}_{2}$ during the test of reducing the amount of clothing changed significantly different between two groups. It is interesting that the oxygen consumption decreased about $0.5 \mathrm{ml} / \mathrm{min} / \mathrm{kg}$ from Step I to Step II then maintained almost $0.6 \mathrm{ml} / \mathrm{min} / \mathrm{kg}$ in males, while it maintained almost steady during first two steps then decreased approximately $0.2 \mathrm{ml} / \mathrm{min} /$ $\mathrm{kg}$ from Step III to Step IV in females.

Table 3. Average of oxygen consumption, rectal temperature $\left(T_{r e}\right)$, mean skin temperature $\left(\bar{T}_{\text {sk }}\right)$ during Step $I$ through Step IV

\begin{tabular}{|c|c|c|c|c|c|c|c|c|}
\hline & \multicolumn{2}{|c|}{ Step I } & \multicolumn{2}{|c|}{ Step II } & \multicolumn{2}{|c|}{ Step III } & \multicolumn{2}{|c|}{ Step IV } \\
\hline & Male & Female & Male & Female & Male & Female & Male & Female \\
\hline $\mathrm{T}_{\mathrm{re}}\left({ }^{\circ} \mathrm{C}\right)$ & $37.4(0.1)$ & $36.9(0.1)$ & $37.4(0.1)$ & $36.9(0.1)$ & $37.4(0.1)$ & $36.8(0.2)$ & $37.4(0.1)$ & $36.9(0.1)$ \\
\hline t-value & \multicolumn{2}{|c|}{$3.586^{* *}$} & \multicolumn{2}{|c|}{$3.505^{* *}$} & \multicolumn{2}{|c|}{$2.475^{*}$} & \multicolumn{2}{|c|}{$2.638 *$} \\
\hline$\overline{\mathrm{T}}_{\mathrm{sk}}\left({ }^{\circ} \mathrm{C}\right)$ & $32.5(0.1)$ & $31.0(0.1)$ & $32.5(0.1)$ & $30.8(0.3)$ & $32.5(0.1)$ & $30.9(0.2)$ & $32.5(0.1)$ & $31.2(0.7)$ \\
\hline t-value & \multicolumn{2}{|c|}{$8.371 * *$} & \multicolumn{2}{|c|}{$4.692 * *$} & \multicolumn{2}{|c|}{$5.506^{* *}$} & \multicolumn{2}{|c|}{$10.041 * *$} \\
\hline$\dot{\mathrm{V}} \mathrm{O}_{2}(\mathrm{ml} / \mathrm{min} / \mathrm{kg})$ & $3.3(0.3)$ & $2.7(0.2)$ & $2.9(0.2)$ & $2.7(0.2)$ & $2.8(0.2)$ & $2.7(0.2)$ & $2.8(0.2)$ & $2.4(0.2)$ \\
\hline t-value & \multicolumn{2}{|c|}{1.809} & \multicolumn{2}{|c|}{0.534} & \multicolumn{2}{|c|}{0.395} & \multicolumn{2}{|c|}{1.053} \\
\hline
\end{tabular}

Values are mean (SE). ${ }^{*} p<.05, * * p<.01$ 


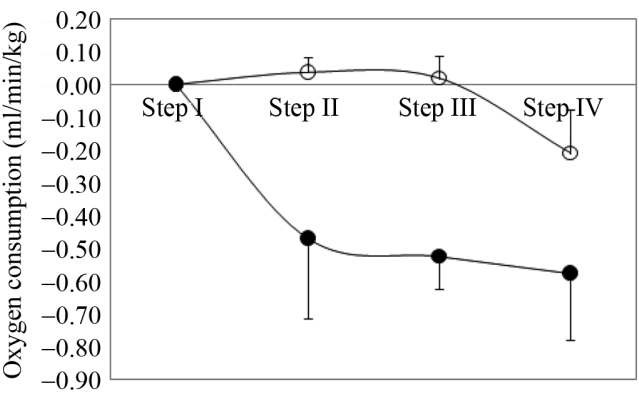

Fig. 2. Change of oxygen consumption $\left(\mathrm{V}_{2}\right)$ during Step I (heavy wearing) through Step IV (light wearing) in males (closed circles) and females (open circles). Values are mean (SE). $p=0.053$

\section{Suggested Amount of Clothing (SAC)}

$\Delta \dot{\mathrm{V}} \mathrm{O}_{2}$ was maintained within $0.1 \mathrm{ml} / \mathrm{min} / \mathrm{kg}$ from Step I to III $(0.02-0.04 \mathrm{ml} / \mathrm{min} / \mathrm{kg})$ in females and from Step II to IV $(-0.47--0.57 \mathrm{ml} / \mathrm{min} / \mathrm{kg})$ in males. Suggested amount of clothing was determined as the critical amount of clothing needed for steady state because it is recommended to wear less in a physiological perspective. Therefore, we obtained the garments weight in Step III for females and Step IV for males in $<$ Fig. 3 $>$ and presented it as SAC in this study.

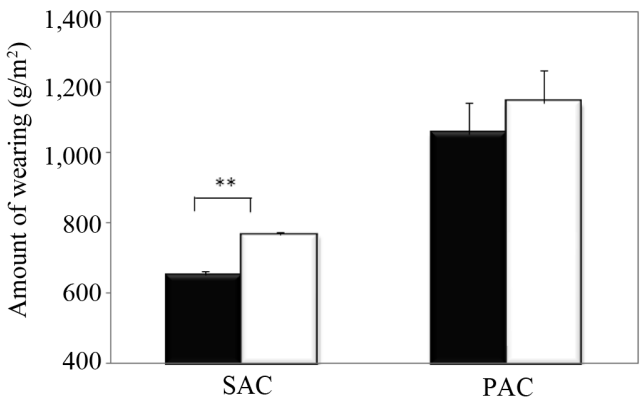

Fig. 3. Suggested and preferred amount of clothing in males (closed bars) and females (open bars). SAC: Suggested amount of clothing, PAC: Preferred amount of clothing. Values are mean (SE). ${ }^{* *} p<.01$

\section{Preferred Amount of Clothing (PAC)}

$<$ Fig. 3> included SAC and PAC of males and females. SAC was 652.0 (SE 9.5) $\mathrm{g} / \mathrm{m}^{2}$ for males and 766.0 (SE 7.6) g/ $\mathrm{m}^{2}$ for females, while PAC was 1053.0 (SE 88.1) g/ $/ \mathrm{m}^{2}$ for males and 1140.6 (SE 92.0) $\mathrm{g} / \mathrm{m}^{2}$ for females. Females showed greater SAC than males $(p<.01)$ but there was no significant difference in PAC between the groups.

\section{Subjective Thermal Sensation and the Cold Climate Adaptability}

The overall thermal sensation is shown in $<$ Table $4>$. Subjects wore the same amount of clothing in Baseline and Step IV, but their overall thermal sensation was not the same. The overall thermal sensation of males ranged 4.5 to 5.5 during the whole test steps except Step I and Step II when they felt slightly warm. Females showed thermal comfort (4.5-5.5) in Baseline and Step II. They felt slightly warm in Step I and Step V, and slightly cool in Step III and cool in Step IV. From the cold climate adaptability questionnaire, females were more sensitive to the cold stress than males $(72 \%$ of males and $92.6 \%$ of females answered as cold sensitive).

\section{Discussion}

Core temperature of the human body maintained through heat exchange between human body and environment. Females were expected lower skin temperature in a cold, because of higher skin insulation by more body fat and higher heat dissipation due to larger body surface area to mass ratio than males (Table 1). From $<$ Table $1>$ and $<$ Table $3>$, females with more body fat kept $\bar{T}_{\mathrm{sk}}$ lower than males, and males with greater skeletal muscle mass kept greater $\Delta \dot{\mathrm{V}} \mathrm{O}_{2}$ than females.

McArdle et al. (1984) found that the cold-induced

Table 4. Overall thermal sensation

\begin{tabular}{c|c|c|c|c|c|c}
\hline \hline & Baseline & Step I & Step II & Step III & Step IV & Step V \\
\hline Male & $4.5(0.3)$ & $4.0(0.4)$ & $4.3(0.3)$ & $4.8(0.2)$ & $5.5(0.2)$ & $5.0(0.3)$ \\
\hline Female & $5.0(0.2)$ & $4.0(0.3)$ & $5.1(0.2)^{\dagger}$ & $5.8(0.4)^{\dagger}$ & $6.6(0.5)^{\dagger}$ & $4.4(0.3)$ \\
\hline
\end{tabular}

Values are mean and SE. ${ }^{\dagger} p<.1$ 
thermogenesis was shown when the rectal temperature decreased more than $1^{\circ} \mathrm{C}$. It isn't likely that the mild cold stress in this study was enough to induce the cold-induced thermogenesis in $\langle$ Fig. 2$\rangle$ since $\Delta \dot{\mathrm{VO}}_{2}$ didn't increase during the whole test periods in reducing amount of garments. Instead, $\Delta \dot{\mathrm{V}} \mathrm{O}_{2}$ dec $\dot{\mathrm{V}} \mathrm{O}_{2}$ reased from step I to step IV for both groups, but the trend of $\Delta \dot{\mathrm{V}} \mathrm{O}_{2}$ was different between two groups. Keatinge (1961) compared the change of metabolic rate before and after cold exposure with two groups, cold exposure group and physical trained group, and found that improved physical fitness reduced the men's early metabolic response to cold. It could support the result of this study that males with better physically fit than females reacted to the cold rapidly by direct reduction of $\Delta \dot{\mathrm{VO}}_{2}$ whether or not it was a part of cold adaptability. Therefore, $\Delta \dot{\mathrm{V}} \mathrm{O}_{2}$ can be a proper tool for determining SAC in this study.

According to Rintamäki (2007), cold climate adaptability is increased by larger body size, abundant subcutaneous fat, good physical fitness, etc. In this point of view, females are morphologically apt to dissipate more heat in a mild cold condition due to higher body surface area to mass ratio than males, as shown in $<$ Table $1>(p<.01)$. The survey on the cold climate adaptability revealed that females are more sensitive to a cold stress to result in the subjective response of overall thermal sensation seen in <Table $4>$. In the study on gender effects during the exposure in warm to cool air temperature, females tended to be cooler than males in cool conditions (Parsons, 2002). Similar result was found from the study on the behavioral thermoregulatory responses of young men and women to the mild cold (Jeong, 2001), in which females selected additional clothing faster than males because of colder sensation. These findings support the result of this study that females tended to be more sensitive to the cold stress than males in Step II through Step IV $(p<.1)$. And it apparently leads to higher insulation by acting as a driving force for the thermoregulatory behavior resulted in warmer sensation in Step V. As a matter of fact, there was gender difference of overall thermal sensation between Step IV and Step V (Table 4) $(p<.05)$. Nevertheless, there was no significant difference in PAC between males and females in $<$ Fig. $3>$,
Table 5. Correlations between overall thermal sensation and the suggested and preferred amount of clothing

\begin{tabular}{c|c|c|c|c}
\hline \hline \multirow{2}{*}{} & \multicolumn{2}{|c|}{ SAC $^{\mathrm{a}}$} & \multicolumn{2}{c}{ PAC $^{\mathrm{b}}$} \\
\cline { 2 - 5 } & $\begin{array}{c}\text { Male } \\
\text { (Step IV) }\end{array}$ & $\begin{array}{c}\text { Female } \\
\text { (Step III) }\end{array}$ & Male & Female \\
\hline $\begin{array}{c}\text { Thermal } \\
\text { sensation }\end{array}$ & 0.147 & -0.554 & -0.461 & -0.807 \\
\hline p-value & 0.780 & 0.122 & 0.357 & 0.009 \\
\hline
\end{tabular}

${ }^{\mathrm{a}}$ Suggested amount of clothing, ${ }^{\mathrm{b}}$ Preferred amount of clothing

which might be because of a large standard deviation between individuals caused by limited number of garment items used. Therefore, it is recommended to conduct a further research on behavioral thermoregulatory responses with various garments of low insulation.

As to amount of clothing per se, SAC was less than PAC both in males and females (Fig. 3). Males and females wore PAC 1.6 and 1.5 times heavier than SAC, respectively. It seems that the subjects rely too much on their subjective thermal sensation and to be deficient in the integrated thermal response. On this point, Jeong and Tokura (1993) reported heavy clothed men exposed to the changing cold environment experienced disturbance of the integration in temperature sensation.

As seen in $\langle$ Table $5>$, however, there was a good correlation between overall thermal sensation and PAC, i.e. thermally comfortable clothing only in females $(p<.01)$. From these results, females seemed to rely too much on thermal sensation in terms of clothing behavior for keeping thermal comfort. In other words, it seems that females respond to cold stress with behavioral thermoregulation adjusting the amount of clothing in this study triggered by subjective thermal sensation prior to the physiological responses. It still remains to be studied whether or not the results of this study is due to the gender difference of body composition. Furthermore, it is necessary to narrow the gap between physiological needs and thermal sensation in order to enhance cold climate adaptability of the individual.

\section{Conclusions}

This study was performed to propose the suggested amount of clothing (SAC) and to observe the preferred amount of clothing (PAC) for thermal comfort in a 
mild cold condition. Six male and nine female college students were exposed to the mild cold condition by stepwise reducing the amount of clothing. Oxygen consumption, rectal temperature, and skin temperature were measured and subjective thermal sensation was voted in each step of five steps. PAC was obtained from the garments weight selected by each subject at the end of the steps.

As a result, we found the gender difference in cold climate adaptability. Females were more sensitive to a cold condition. Females tended to prefer higher insulation in a mild cold condition to perceive thermal comfort. The PAC was 1053.0 (SE 88.1) g/ $\mathrm{m}^{2}$ for males and 1140.6 (SE 92.0) $\mathrm{g} / \mathrm{m}^{2}$ for females. SAC was determined as the critical amount of clothing needed for steady state and derived it from $\Delta \dot{\mathrm{V}} \mathrm{O}_{2} \mathrm{SAC}$ was also higher in females $\left(766.0(\mathrm{SE} 7.6) \mathrm{g} / \mathrm{m}^{2}\right)$ than males $\left(652.0(\mathrm{SE} 9.5) \mathrm{g} / \mathrm{m}^{2}\right)$. From this study, we found that there was a difference between PAC and SAC for both groups. Therefore it is recommended to reduce the difference in PAC and SAC in order to enhance individual's cold climate adaptability.

\section{References}

Celi, F. S., Brychta, R. J., Linderman, J. D., Butler, P. W., Alberobello, A. T., Smith, S., Courville, A. B., Lai, E. W., Costello, R., Skarulis, M. C., Csako, G., Remaley, A., Pacak, K., \& Chen, K. Y. (2010). Minimal changes in environmental temperature result in a significant increase in energy expenditure and changes in the hormonal homeostasis in healthy adults. European Journal of Endocrinology, 163(6), 863-872.

Dauncey, M. J. (1981). Influence of mild cold on $24 \mathrm{~h}$ energy expenditure, resting metabolism and diet-induced thermogenesis. British Journal of Nutrition, 45, 257267.

Glickman-Weiss, E. L., Goss, F. L., Robertson, R. J., Metz, K. F., \& Cassinelli, D. A. (1991). Physiological and thermal responses of males with varying body compositions during immersion in moderately cold water. Aviation Space and Environmental Medicine, 62(11), 10631067.

Glickman-Weiss, E. L., Hearon, C. M., Prisby, R., \& Caine, N. (1998). The perceptual and physiological responses of high and low fat women exposed to $5^{\circ} \mathrm{C}$ air for 120 minutes. Wilderness and Environmental Medicine, 9(4), 204-210.
Glickman-Weiss, E. L., Nelson, A. G., Hearon, C. M., Prisby, R., \& Caine, N. (1999). Thermal and metabolic responses of women with high fat versus low fat body composition during exposure to 5 and 27 degrees $\mathrm{C}$ for $120 \mathrm{~min}$. Aviation Space and Environmental Medicine, 70(3 Pt 1), 284-288.

Jeong, W. S. (2001). Gender difference of clothing selection behavior for thermal comfort. Journal of the Korean Society of Living Environmental System, 8(2), 189-193.

Jeong, W. S., \& Tokura, H. (1993). Different thermal conditions of the extremities affect thermoregulation in clothed man. European Journal of Applied Physiology, $67,481-485$.

Keatinge, W. R. (1961). The effect of repeated daily exposure to cold and of improved physical fitness on the metabolic and vascular response to cold air. Journal of Physiology, 157, 209-220.

LeBlanc, J. (1975). Man in the cold. Springfield, Illinois: Charles C Thomas.

McArdle, W. D., Magel, J. R., Gergley, T. J., Spina, R. J., \& Toner, M. M. (1984). Thermal adjustment to cold-water exposure in resting men and women. Journal of Applied Physiology, 56(6), 1565-1571.

McCullough, E. A., Jones, B. W., \& Huck, J. (1985). A comprehensive data for estimating clothing insulation. ASHRAE Transactions, 91, 29-47.

Parsons, K. C. (2002). The effects of gender, acclimation state, the opportunity to adjust clothing and physical disability on requirements for thermal comfort. Energy and Buildings, 34, 593-599.

Prisby, R., Glickman-Weiss, E. L., \& Caine, N. (2000). Thermal sensation and substrate utilization differs among low- and high-fat women exposed to 17 degrees $\mathrm{C}$ water. Wilderness and Environmental Medicine, 11(3), 157-162.

Prisby, R., Glickman-Weiss, E. L., Nelson, A. G., \& Caine, N. (1999). Thermal and metabolic responses of high and low fat women to cold water immersion. Aviation Space and Environmental Medicine, 70(9), 887-891.

Rintamäki, H. (2007). Human responses to cold. Alaska Medicine, 49(2), 29-31.

Scholander, P. F., Hock, R., Walters, V., Johnson, F., \& Irving, L. (1950). Heat regulation in some arctic and tropical mammals and birds. The Biological Bulletin, 99, 237-258

Stock, J. M., Taylor, N. A. S., Tipton, M. J., \& Greenleaf, J. E. (2004). Human physiological responses to cold exposure. Aviation Space and Environmental Medicine, 75(5), 444-457.

Toner, M. M., Sawka, M. N., Foley, M. E., \& Pandolf, K. B. (1986). Effects of body mass and morphology on thermal responses in water. Journal of Applied Physiology, 60(2), $521-525$ 